\title{
Staurosporine-induced programmed cell death in Blastocystis occurs independently of caspases and cathepsins and is augmented by calpain inhibition
}

\author{
Correspondence \\ Kevin S. W. Tan \\ mictank@nus.edu.sg
}

Received 22 August 2009

Revised 17 December 2009

Accepted 3 January 2010
Jing Yin, Josephine Howe and Kevin S. W. Tan

Laboratory of Molecular and Cellular Parasitology, Department of Microbiology, Yong Loo Lin School of Medicine, National University of Singapore, 5 Science Drive 2, Singapore

\begin{abstract}
Previous studies have shown that the protozoan parasite Blastocystis exhibits apoptotic features with caspase-like activity upon exposure to a cytotoxic monoclonal antibody or the anti-parasitic drug metronidazole. The present study reports that staurosporine (STS), a common apoptosis inducer in mammalian cells, also induces cytoplasmic and nuclear features of apoptosis in Blastocystis, including cell shrinkage, phosphatidylserine (PS) externalization, maintenance of plasma membrane integrity, extensive cytoplasmic vacuolation, nuclear condensation and DNA fragmentation. STS-induced PS exposure and DNA fragmentation were abolished by the mitochondrial transition pore blocker cyclosporine $A$ and significantly inhibited by the broad-range cysteine protease inhibitor iodoacetamide. Interestingly, the apoptosis phenotype was insensitive to inhibitors of caspases and cathepsins B and L, while calpain-specific inhibitors augmented the STS-induced apoptosis response. While the identities of the proteases responsible for STSinduced apoptosis warrant further investigation, these findings demonstrate that programmed cell death in Blastocystis is complex and regulated by multiple mediators.
\end{abstract}

\section{INTRODUCTION}

Programmed cell death (PCD) has long been recognized as an essential process to eliminate unwanted or damaged cells and thus ensure normal growth and development in multicellular organisms (Baehrecke, 2002; Hengartner, 2000). It was assumed that PCD arose with multicellular organisms (Vaux et al., 1994). However, considerable experimental evidence supports the existence of PCD in unicellular eukaryotes. These include non-parasitic organisms, such as yeast (Madeo et al., 2002), the free-living slime mould Dictyostelium discoideum (Arnoult et al., 2001; Cornillon et al., 1994), the free-living ciliate Tetrahymena thermophila (Christensen et al., 1998; Kobayashi \& Endoh, 2005) and the dinoflagellate Peridinium gatunense (Vardi et al., 1999). In parasitic organisms, PCD has been described in the kinetoplastid trypanosomes (Ameisen et al., 1995; Welburn et al., 1996) and Leishmania (Arnoult

Abbreviations: ALLN, N-acetyl-L-leucinyl-L-leucinyl-L-norleucinal; BrdU, bromodeoxyuridine; BrdUTP, 5-bromo-2'-deoxyuridine 5'-triphosphate; CA-074Me, (L-3-trans-(propylcarbamyl)oxirane-2-carbonyl)-L-isoleucylL-proline methyl ester; CsA, cyclosporine A; E64D, (2S,3S)-transepoxysuccinyl-L-leucylamido-3-methylbutane ethyl ester; IA, iodoacetamide; PCD, programmed cell death; PI, propidium iodide; PS, phosphatidylserine; STS, staurosporine; TEM, transmission electron microscopy; TUNEL, terminal deoxynucleotidyl transferase-mediated dUTP nick-end labelling; z-FA.fmk, Z-Phe-Ala fluoromethyl ketone; z-FF.fmk, Z-PhePhe-fluoromethyl ketone; z-LLL.fmk, Z-Leu-Leu-Leu-fluoromethyl ketone; $\quad$-VAD.fmk, N-benzyloxycarbonyl-Val-Ala-Asp(O-Me) fluoromethyl ketone. et al., 2002; Bera et al., 2003; Zangger et al., 2002), the apicomplexan parasite Plasmodium (Al-Olayan et al., 2002; Deponte \& Becker, 2004), Tritrichomonas (Mariante et al., 2006) and Blastocystis (Tan \& Nasirudeen, 2005).

Unicellular protozoan parasites cause a wide variety of human diseases. The current treatment of these infections is being challenged by an increasing incidence of drug resistance and a lack of effective vaccines (Croft et al., 2006; Fidock et al., 2008). The investigation of PCD pathways in these organisms might lead to the discovery of novel parasite control strategies (Alvarez et al., 2008; Deponte \& Becker, 2004). However, despite the many morphological and biochemical studies of PCD in protozoan parasites, most of the homologues of mammalian molecules involved in cell death signalling are missing in the protozoa, and the molecular architecture of PCD in protozoan parasites therefore remains puzzling.

Blastocystis is a unicellular protozoan parasite found in the intestines of humans and many animals (Tan, 2004, 2008). It is transmitted through the faecal-oral route and is prevalent in areas with poor hygiene, and deficient sanitation services and facilities. The pathogenicity of this organism is still controversial due to the variability of diagnostic tests and our lack of understanding of the differences in virulence among subtypes (Stensvold et al., 2009). Nonetheless, growing evidence suggests that Blastocystis can be an opportunistic pathogen in immunocompromised individuals (Andiran et al., 2006; Cirioni 
et al., 1999; Tasova et al., 2000). Previously, our laboratory has shown that Blastocystis displays characteristics of PCD when treated with a surface-reactive cytotoxic monoclonal antibody or metronidazole, a drug commonly used to treat Blastocystis infections in humans (Nasirudeen et al., 2001b, 2004).

The present study reveals that staurosporine (STS), which can induce apoptosis in all mammalian cells and the pathways of which have been extensively studied (Weil et al., 1996; Zhang et al., 2004), can also induce PCD in Blastocystis. Furthermore, the apoptotic mechanisms and regulation of this STS-induced cell death pathway in Blastocystis are described.

\section{METHODS}

Culture of organism. Blastocystis subtype 7 (previously known as Blastocystis hominis isolate B) was isolated from a local patient stool sample and axenized (Ho et al., 1993). Cells were cultured in Iscove's modified Dulbecco's medium (IMDM) containing $10 \%$ inactive horse serum and incubated anaerobically at $37{ }^{\circ} \mathrm{C}$ in an Anaerojar (Oxoid). Cells were subcultured at 3-4 day intervals and 4 day old cells at exponential phase were used for all experiments.

Treatment with STS to induce cell death. Cells were cultured into IMDM at a concentration of $2 \times 10^{6}$ cells $\mathrm{ml}^{-1}$. STS $(1 \mathrm{mM}$ stock in DMSO, Sigma) was then added to a final concentration of $1 \mu \mathrm{M}$, and the cells were incubated with STS for 3 or $12 \mathrm{~h}$ for flow cytometry analysis and ultrastructural studies. A necrotic control was done by heating cells at $80{ }^{\circ} \mathrm{C}$ for $15 \mathrm{~min}$. Protease inhibitors or cyclosporine A (CsA) were added $30 \mathrm{~min}$ before the addition of STS in some experiments. The protease inhibitors used were: $N$-benzyloxycarbonylVal-Ala-Asp (O-Me) fluoromethyl ketone (z-VAD.fmk); Z-Phe-Ala fluoromethyl ketone (z-FA.fmk); Z-Phe-Phe-fluoromethyl ketone (zFF.fmk); (L-3-trans-(propylcarbamyl)oxirane-2-carbonyl)-L-isoleucylL-proline methyl ester (CA-074Me); Z-Leu-Leu-Leu-fluoromethyl ketone (z-LLL.fmk); N-acetyl-L-leucinyl-L-leucinyl-L-norleucinal (ALLN); epoxomicin; and (2S,3S)-trans-epoxysuccinyl-L-leucylamido-3-methylbutane ethyl ester (E64D) (all were obtained from Sigma, diluted in DMSO, and used at $50 \mu \mathrm{M}$ unless otherwise stated). Iodoacetamide (IA) was purchased from Bio-Rad and diluted in water. CsA (Sigma) was diluted in DMSO and used at $10 \mu \mathrm{M}$.

Annexin V-FITC and propidium iodide (PI) staining. Membrane permeability and exposure of phosphatidylserine (PS) were analysed using an Annexin V-FITC apoptosis detection kit (BioVision) following the manufacturer's instructions. In brief, cells treated with STS for $3 \mathrm{~h}$ alone or in the presence of various inhibitors as described above for $3 \mathrm{~h}$ were washed with cold PBS and resuspended in $500 \mu \mathrm{l}$ calciumcontaining binding buffer. Annexin V-FITC and PI ( $5 \mu \mathrm{l}$ of each) were added to the cell suspension and incubated at room temperature for $10 \mathrm{~min}$. The cells were analysed by a flow cytometer (Dako CyAn ADP) with a $488 \mathrm{~nm}$ argon-ion laser. Annexin V-FITC was detected using an emission filter of 530/40 nm and PI was detected using an emission filter of $613 / 20 \mathrm{~nm}$. Alternatively, cells were mounted on a glass slide with a coverslip and examined with a fluorescence microscope (Olympus BX60) using a $495 \mathrm{~nm}$ excitation filter and a $525 \mathrm{~nm}$ emission filter for Annexin V-FITC, and $577 \mathrm{~nm}$ excitation filter and $590 \mathrm{~nm}$ emission filter for PI. The images were captured by a charge-coupled device (CCD) camera (Olympus DP70) connected to the microscope.

Terminal deoxynucleotidyl transferase-mediated dUTP nickend labelling (TUNEL) assay. TUNEL was performed using an APO-
BrdU kit (Invitrogen). In brief, cells treated with STS for $12 \mathrm{~h}$ alone or in the presence of various inhibitors as described above for $12 \mathrm{~h}$ were harvested, washed with cold PBS and fixed with $1 \mathrm{ml} 3.7 \%(\mathrm{v} / \mathrm{v})$ formaldehyde on ice for $30 \mathrm{~min}$. After two washes with PBS, the pellet was resuspended in $1 \mathrm{ml} 70 \%$ cold ethanol at $-20{ }^{\circ} \mathrm{C}$ for $30 \mathrm{~min}$ to permeabilize cells. The cells were washed and incubated with $50 \mu \mathrm{l}$ labelling solution containing 5-bromo- 2 '-deoxyuridine 5 '-triphosphate (BrdUTP) and terminal deoxynucleotidyl transferase at $37^{\circ} \mathrm{C}$ for $1 \mathrm{~h}$. After rinsing, cells were stained with AlexaFluor 488-conjugated antibromodeoxyuridine (BrdU) antibody at room temperature for $30 \mathrm{~min}$. The cells were washed, resuspended in $500 \mu \mathrm{l}$ PBS and analysed by a flow cytometer (Dako CyAn ADP) using a $488 \mathrm{~nm}$ argon-ion laser. Green fluorescence was detected using an emission filter of 530/40 nm.

Transmission electron microscopy (TEM). The ultrastructural features of Blastocystis cells under various treatments were examined using TEM. Briefly, cells were fixed with $2 \%$ glutaraldehyde and $2 \%$ paraformaldehyde in PBS for $3 \mathrm{~h}$ at $4{ }^{\circ} \mathrm{C}$. The cells were then pelleted at $1000 \mathrm{~g}$ for $5 \mathrm{~min}$, washed twice with PBS and twice with deionized water. After each washing step, cells were spun at $1500 \mathrm{~g}$ and the supernatant was discarded. Cells were then post-fixed for $2 \mathrm{~h}$ with $1 \%$ osmium tetroxide containing $1 \%$ potassium ferrocyanide at room temperature, followed by dehydration with a graded ethanol series, infiltration and embedding with LR White resin. Ultrathin sections were stained with uranyl acetate and lead citrate, and examined using an EM208S transmission electron microscope (Philips).

Calpain activity assay. The calpain activity assay was performed using the Calpain Activity Assay kit (BioVision) according to the manufacturer's protocol. Briefly, cells were treated with STS for $3 \mathrm{~h}$ alone or in the presence of different inhibitors. For each condition, $2 \times 10^{6}$ cells were pelleted, and the pellets were resuspended and incubated in the supplied extraction buffer on ice for $20 \mathrm{~min}$. After centrifugation at $10000 \mathrm{~g}$ for $1 \mathrm{~min}$, the clear lysates were transferred to a 96-well microplate, mixed with the fluorogenic calpain substrate Ac-LLY-AFC and incubated for $1 \mathrm{~h}$ at $37{ }^{\circ} \mathrm{C}$ in the dark. Fluorescence intensity was determined at $400 \mathrm{~nm}$ excitation and $505 \mathrm{~nm}$ emission by a Tecan fluorescence plate reader.

Reproducibility of results and statistical analysis. All experiments were repeated at least three times, except for TEM analysis, which was performed once. Quantitative data were statistically evaluated using Student's $t$ test and the level of significance was set at $P<0.05$.

\section{RESULTS AND DISCUSSION}

\section{STS triggers apoptotic features in Blastocystis}

STS, a protein kinase inhibitor, has been shown to induce PCD in all mammalian cells studied so far (Weil et al., 1996; Zhang et al., 2004) and is a valuable tool in PCD studies. STS at a concentration of $1 \mu \mathrm{M}$ induced in Blastocystis a rapid cell death process with apoptotic features. As shown in Fig. 1(a), flow cytometry analysis of STS-treated cells showed a reduction in cell size at $3 \mathrm{~h}$. The dot plot of side scatter versus forward light scatter of untreated cells displayed two distinct populations of cells, which have previously been observed in flow cytometry analysis of Blastocystis (Nasirudeen et al., 2001b, 2004). The population on the right was a mixture of healthy cells and those undergoing programmed cell death, while the population on the left was dead cells and cellular debris. When treated with STS, the population on the right shifted towards the left, indicating cell shrinkage. The 
(a)
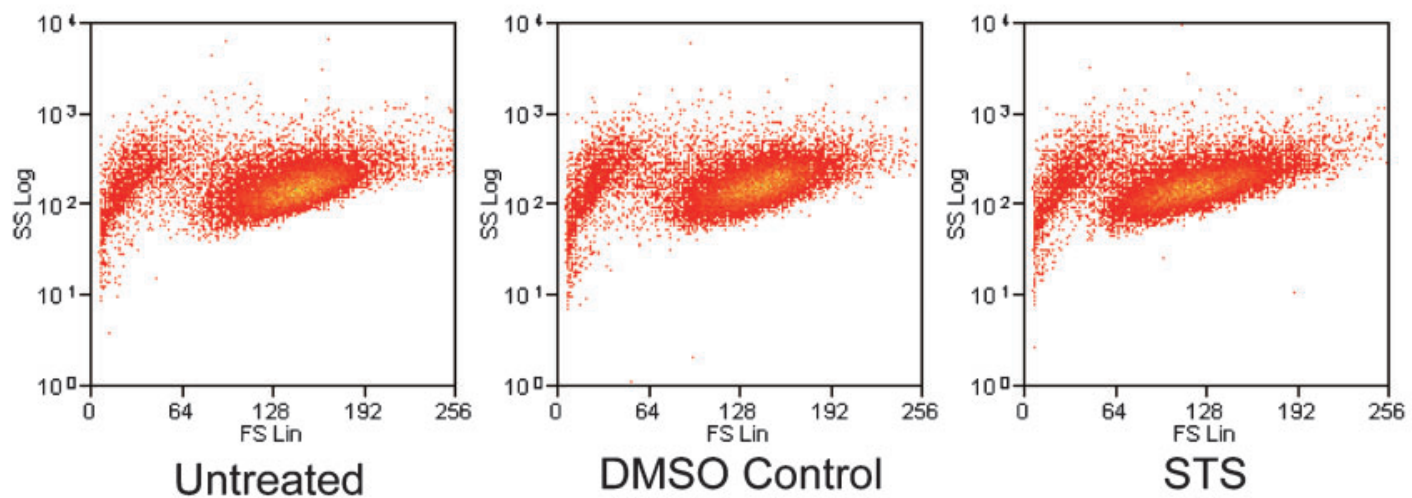

(b)

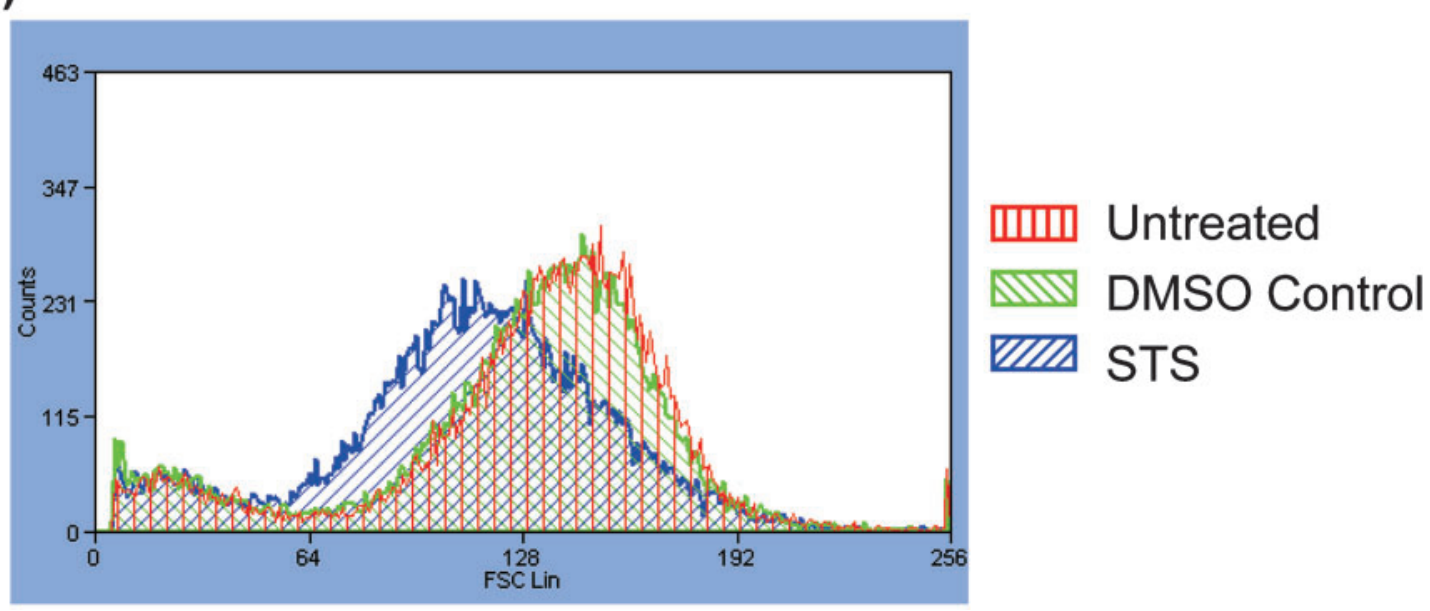

Fig. 1. Effect of STS on Blastocystis cell size as analysed by flow cytometry. Blastocystis cells were incubated in the absence (Untreated) or presence of $1 \mu \mathrm{M}$ STS for $3 \mathrm{~h}$. The DMSO control is the vehicle control. (a) Dot plots of side scatter (SS) (granularity) versus forward scatter (FS) (size). (b) Histogram representation of cell size.

histogram of forward size scatter (Fig. 1b) also showed that STS-treated cells were smaller than controls. The decrease in cell volume is an important early event of apoptosis that distinguishes it from necrosis (Bortner \& Cidlowski, 1998).

Blastocystis cells exposed to STS maintained membrane integrity while they exhibited PS externalization, two further characteristics of apoptotic cells (Fig. 2). PI, when used in the absence of a cell permeant, can only enter cells with damaged plasma membranes, after which it stains the nucleic acid. Exclusion of PI demonstrates the preservation of membrane integrity. The combined use of PI and Annexin V, which binds to PS exposed on the outer layer of the plasma membrane during apoptosis, can differentiate apoptotic, necrotic and healthy cells. As shown by flow cytometry analysis in Fig. 2(a), a very low percentage of STStreated cells showed PI-positive staining, similar to that of untreated and vehicle control cells. In contrast, heat-induced necrotic cells showed a very high percentage $(86.31 \%)$ of PIpositive cells. While maintaining membrane integrity, STS- treated cells had a $33.17 \%$ subpopulation with Annexin Vpositive and PI-negative staining, much higher than that of untreated and DMSO control cells (2.92 and 4.87\%, respectively). The response was rapid, as Blastocystis was treated with STS for only $3 \mathrm{~h}$. The fluorescent microscopy images in Fig. 2(b) show that in Blastocystis cells treated with STS, Annexin V bound to the outer layer of the plasma membrane, since these cells had intact plasma membranes, as shown by the negative PI staining.

DNA fragmentation is a hallmark of apoptosis and usually a late event in apoptosis (Collins et al., 1997). The TUNEL assay relies on the specific binding of terminal deoxynucleotidyl transferase to exposed $3^{\prime}-\mathrm{OH}$ ends of DNA followed by the synthesis of a labelled deoxyuridine molecule. Hence, formation of DNA strand breaks as a consequence of endonuclease activity can be detected by flow cytometry analysis and expressed as a percentage of TUNEL-positive cells. As shown in Fig. 3, cells treated with STS for $12 \mathrm{~h}$ exhibited $56.09 \%$ TUNEL-positivity, whereas 
(a)
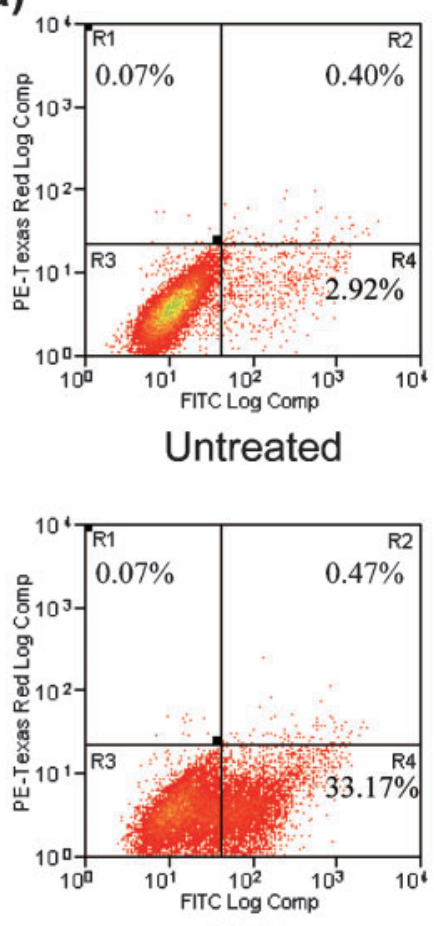

STS

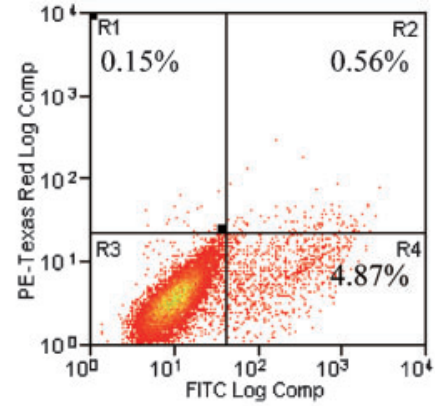

DMSO Control

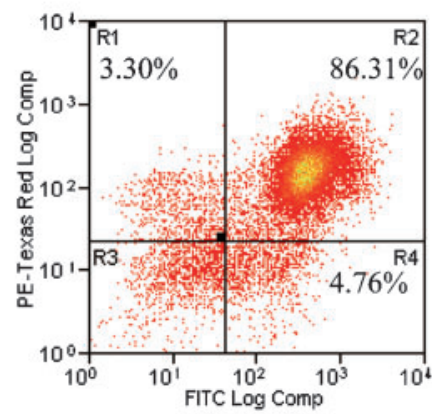

Necrotic control

(b)

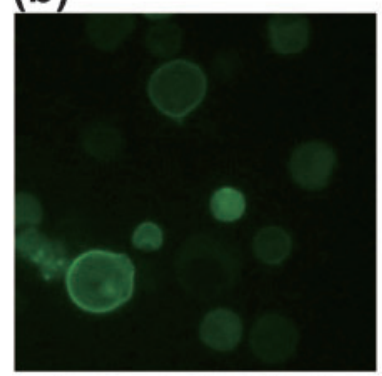

Annexin V-FITC

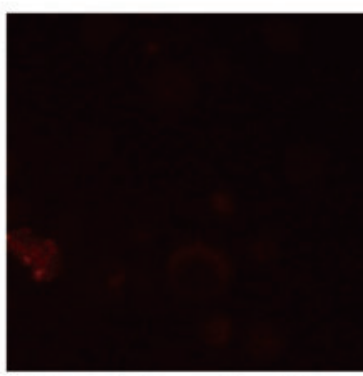

Propidium iodide

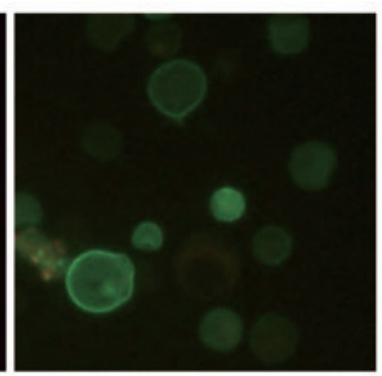

Merge

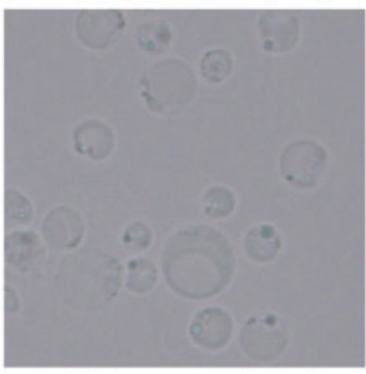

Phase contrast

Fig. 2. Preservation of membrane integrity and externalization of PS in cells treated with STS. Blastocystis cells were incubated in the absence (Untreated) or presence of $1 \mu \mathrm{M}$ STS for $3 \mathrm{~h}$. The DMSO control is the vehicle control. Necrosis was induced by heating the cells in an $80{ }^{\circ} \mathrm{C}$ water bath for $15 \mathrm{~min}$. Cells were stained with Annexin V-FITC to detect PS on the cell surface and PI was used to stain cells with compromised plasma membranes. (a) Representative dot plots of Annexin V-FITC and PI staining assay analysed by a flow cytometer. The R4 quadrant represents the percentage of apoptotic cells (Annexin V-FITC-positive/PInegative cells) in the total cell population. $x$ Axis, FITC fluorescence; $y$ axis, PI fluorescence. (b) Fluorescent microscopy images of STS-treated cells stained by Annexin V-FITC and PI.

untreated cells or vehicle controls had much lower percentages of TUNEL-positive cells.

Transmission electron micrographs of STS-treated cells also revealed apoptotic features. As compared with the healthy control, cells exposed to STS for $3 \mathrm{~h}$ showed massive cytoplasmic vacuolation (Fig. 4b). After $12 \mathrm{~h}$ treatment with STS, cells still exhibited cytoplasmic vacuolation (Fig. 4c, d), while margination and segregation of nuclear chromatin was observed in some cells (Fig. 4d). Large cytoplasmic vacuoles coalesced with the central vacuole in some cells (Fig. 4e), while condensed cells with collapsed central vacuoles were also observed (Fig. 4f). Therefore, these results demonstrate that as in mammalian cells, STS is a strong apoptosis inducer for Blastocystis.

\section{Regulation of STS-induced apoptosis by mitochondria and cysteine proteases}

Since STS was found to be a strong and robust inducer of apoptotic cell death in Blastocystis, it was used to screen 

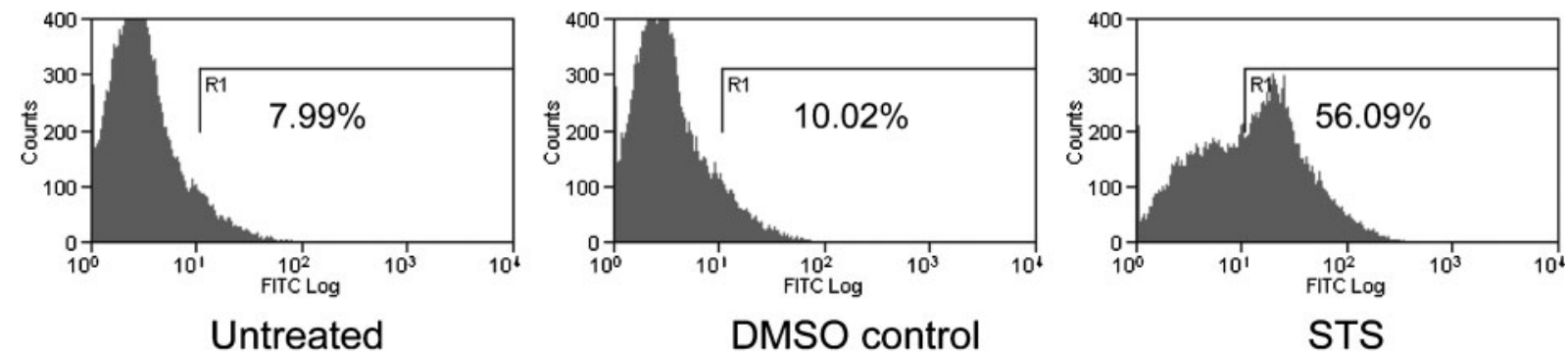

Fig. 3. Representative histograms showing in situ DNA fragmentation analysis (TUNEL) of Blastocystis cells by flow cytometry. Cells were treated with $1 \mu \mathrm{M}$ STS for $12 \mathrm{~h}$. DNA fragmentation was detected with BrdUTP, labelled with AlexaFluor 488conjugated anti-BrdU antibody, and analysed by a flow cytometer. R1 represents the percentage of cells with DNA fragmentation. STS-treated cells had a significant increase in fluorescence intensity compared with the untreated control or vehicle (DMSO) control. $x$ Axis, FITC fluorescence.

potential regulators of Blastocystis PCD. The mitochondrion and cysteine proteases are the key regulators of apoptosis in higher eukaryotes. Therefore, the mitochondrial transition pore blocker CsA and inhibitors of a range of cysteine proteases were used to pretreat the cells before their exposure to STS (Figs 5, 6 and 7). STS-treated Blastocystis showed $55.3 \pm 3 \%$ cells with PS exposure at $3 \mathrm{~h}$ and $51.3 \pm 1.7 \%$ cells with in situ DNA fragmentation at $12 \mathrm{~h}$ (Fig. 7). CsA completely abolished STS-induced PS exposure and DNA fragmentation. The general cysteine protease inhibitor IA in the concentration range of 10 to $100 \mu \mathrm{M}$ could inhibit the two apoptotic features in a dose-dependent
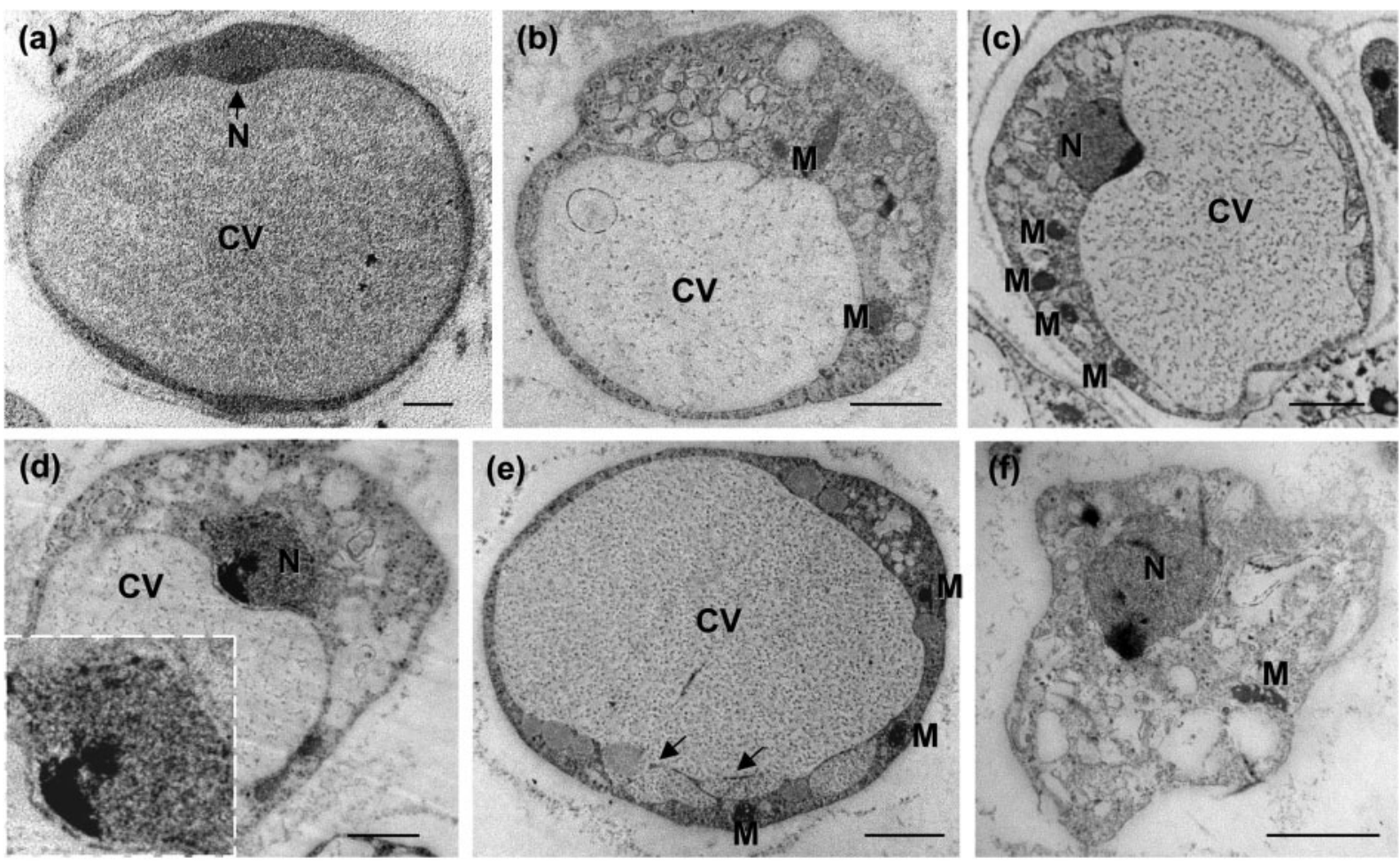

Fig. 4. TEM of Blastocystis cells exposed to STS for 3 or 12 h. (a) Healthy Blastocystis cell with normal morphology and DNA chromatin seen as a crescentic mass. (b, c) Massive cytoplasmic vacuolation in a cell treated with STS for $3 \mathrm{~h}$ (b) or $12 \mathrm{~h}$ (c). (d) Condensed and segregated chromatin in a cell treated with STS for $12 \mathrm{~h}$; inset, enlarged image of its nucleus. (e) Coalescing of large cytoplasmic vacuoles (arrows) with central vacuole in a cell treated with STS for $12 \mathrm{~h}$. (f) Cell treated with STS for $12 \mathrm{~h}$ displaying collapsed central vacuole, apparent severe shrinkage and multiple vacuoles. $\mathrm{N}$, nucleus; CV, central vacuole; M, mitochondrion. Bars, $2 \mu \mathrm{m}$. 

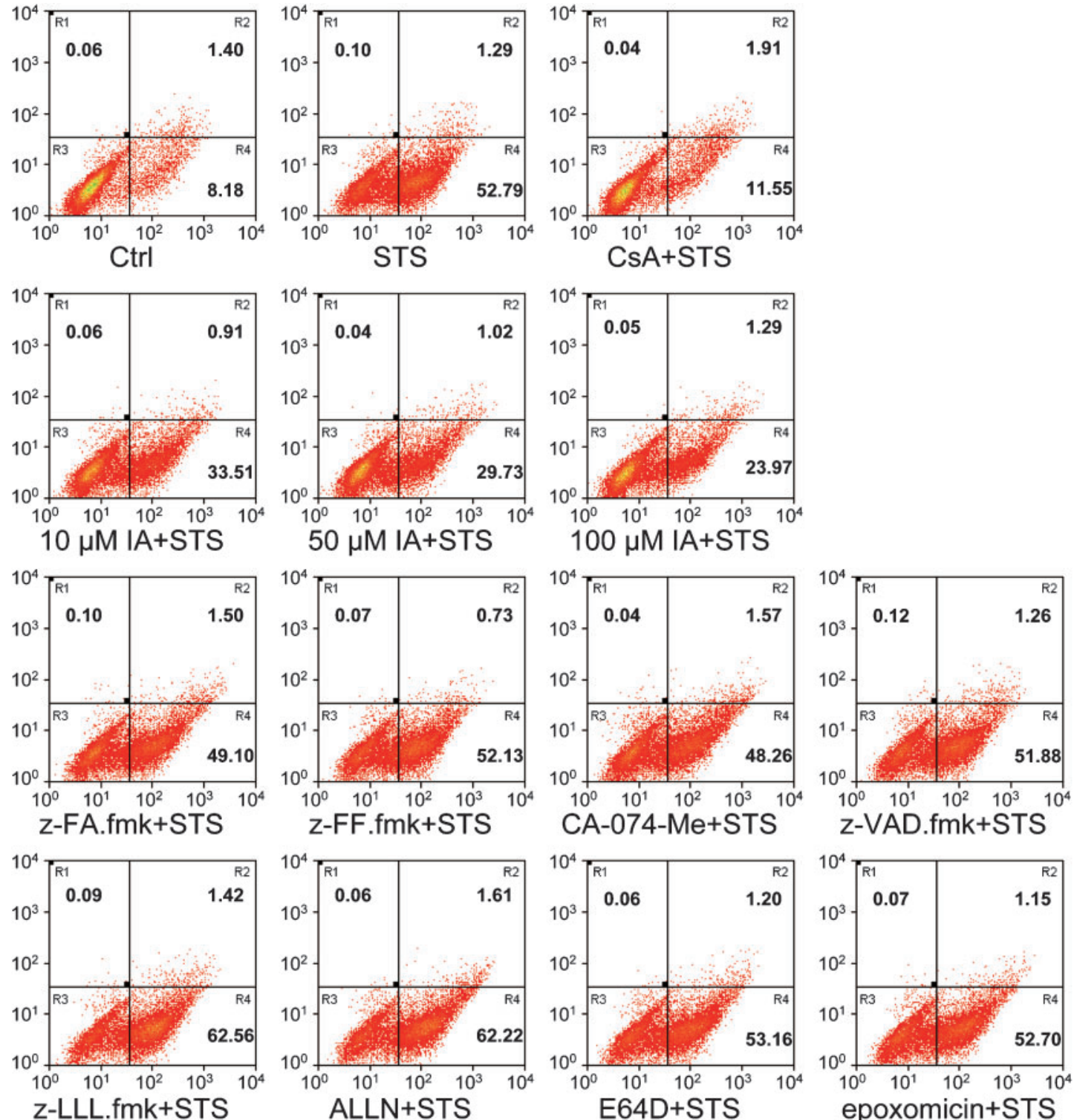

Fig. 5. Annexin $V$ assay of inhibitor-pretreated cells. Cells were pretreated with various protease inhibitors or CsA for $30 \mathrm{~min}$ before incubation with STS for $3 \mathrm{~h}$. Cells were stained with Annexin V-FITC and PI, and analysed by a flow cytometer. The R4 quadrant represents the percentage of apoptotic cells (Annexin V-FITC-positive/PI-negative cells) in the total cell population. The control was performed with the same volume of diluent (DMSO). $x$ Axis, FITC fluorescence; $y$ axis, PI fluorescence.

manner. However, even with the highest concentration of $100 \mu \mathrm{M}$, IA could only reduce the percentage of Annexin Vpositive cells and TUNEL-positive cells to $25.6 \pm 3.8$ and $22.7 \pm 3.1 \%$, respectively, and was thus not as effective as CsA. The effects of more specific inhibitors of different families of cysteine proteases were also investigated. The caspase inhibitor z-VAD.fmk and cathepsin B and L inhibitors z-FF.fmk, z-FA-fmk and CA-074-Me could not inhibit STS-induced changes in PS exposure and DNA fragmentation. Interestingly, two calpain inhibitors, ZLLL.fmk and ALLN, could promote STS-induced apoptotic responses, evidenced by the increase of PS exposure to $65.3 \pm 2.6 \%$ (z-LLL.fmk) and 64.6 $\pm 2.2 \%$ (ALLN), and increased DNA fragmentation to $64.0 \pm 2.9 \%$ (z-LLL.fmk) and $62.7 \pm 2.0 \%$ (ALLN). However, because it has been reported that the calpain inhibitor ALLN may also inhibit the proteosome (McDonald et al., 2001), the effect of the proteosome inhibitor epoxomicin was also tested. No inhibition of STS-induced apoptotic features could be observed with epoxomicin pretreatment, indicating that the apoptosis-promoting effect of calpain inhibitors should be due specifically to the inhibition of calpain activity. 

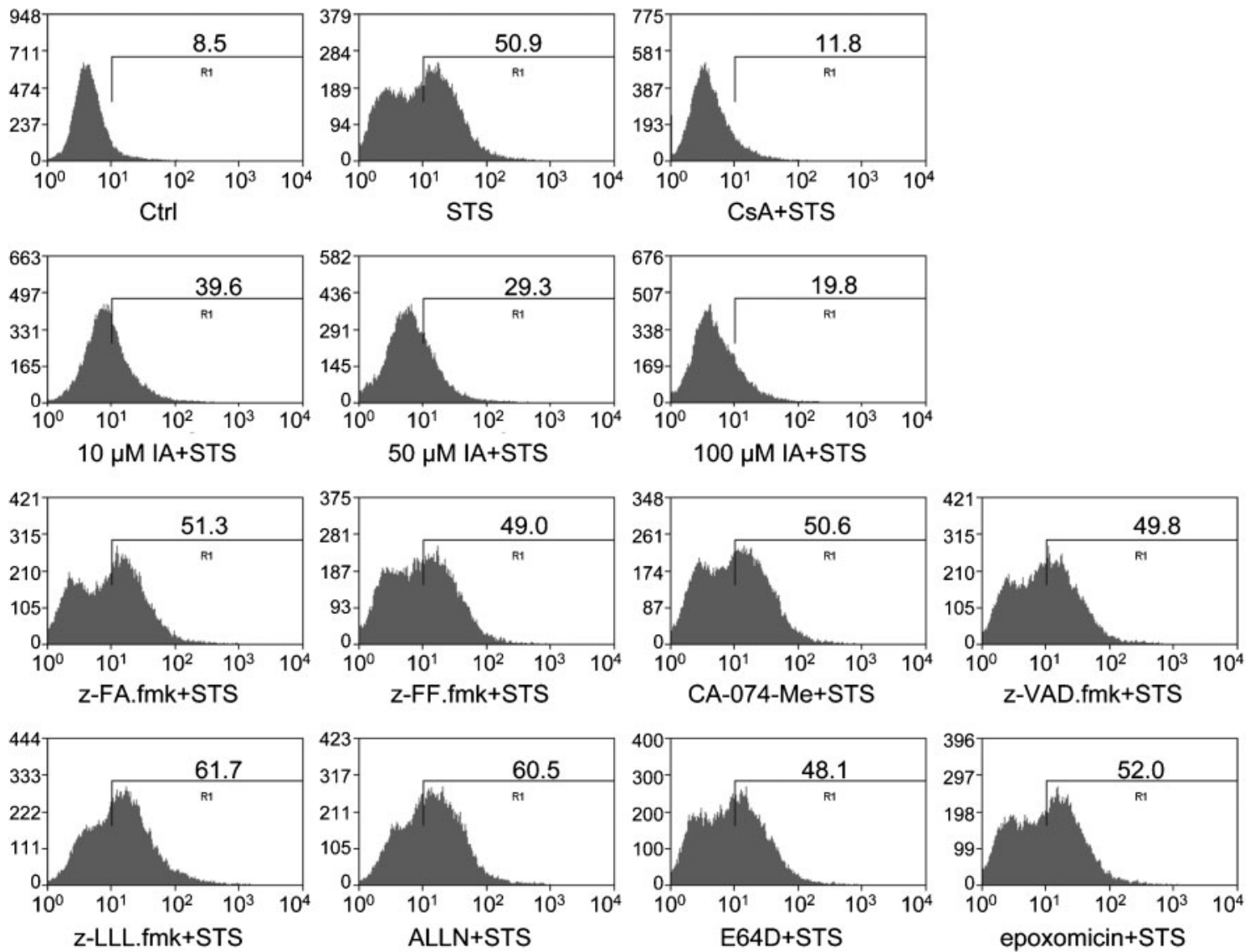

Fig. 6. TUNEL assay of inhibitor-pretreated cells. Cells were pretreated with various protease inhibitors or CsA for 30 min before incubation with STS for $12 \mathrm{~h}$. The gated population represents the percentage of apoptotic cells (TUNEL-positive). DNA fragmentation was detected with BrdUTP and labelled with AlexaFluor 488-conjugated anti-BrdU antibody. Cells were analysed by a flow cytometer. R1 represents the population of cells with DNA fragmentation. The control was performed with the same volume of diluent (DMSO). $x$ Axis, FITC fluorescence; $y$ axis, cell count.

Since calpain inhibitors were found to augment STSinduced apoptotic responses, the activity of calpain was assessed to see whether there is any correlation between calpain activity and the apoptotic responses. As shown in Fig. 7(c), calpain is constitutively active in healthy cells. However, exposure to STS greatly increased calpain activity to double that of the control. As expected, the calpain inhibitors z-LLL.fmk and ALLN completely inhibited the enzymic activity of this protease. Therefore, the data suggest that Blastocystis calpain becomes more active upon exposure of cells to STS and exerts a protective effect against the STS challenge. The general cysteine protease inhibitor IA could inhibit the STS-induced apoptotic responses to some extent, whereas E64D, a broad-range inhibitor of cathepsins and calpains had no inhibitory effect. The different effects of these two protease inhibitors on STS-induced apoptotic responses might be explained by their different inhibitory profiles on calpain activity. Fig. 7(c) shows that E64D is a potent inhibitor of calpain, while IA inhibited calpain activity only moderately. It is likely that the two inhibitors exert a protective effect on the cells by inhibiting an unknown protease which is responsible for mediating the STS-induced apoptosis; however, the cytoprotective effect of E64D is neutralized by its apoptosis-promoting effect through the inhibition of calpain.

In the present study, we have investigated the PCDinducing potential of STS in Blastocystis and analysed the STS-induced apoptotic signalling pathway. Our results demonstrate that the protein kinase inhibitor STS can induce an apoptotic cell death processes with several cytoplasmic and nuclear features of mammalian apoptosis, including cell shrinkage, exposure of PS molecules, maintenance of plasma membrane integrity, extensive cytoplasmic vacuolation, nuclear condensation and DNA fragmentation.

Apoptosis in mammalian cells is mediated primarily by the activation of a family of cysteine proteases called caspases, which cleave substrates critical for cell survival (Taylor et al., 2008). Another major executionary pathway is through mitochondrial outer membrane permeabilization 


$\begin{array}{lll}1 \text { Ctrl } & 6 \text { IA } 100 \mu M+S T S & 11 \text { z-LLL.fmk+STS } \\ 2 \text { STS } & 7 \text { z-FA.fmk+STS } & 12 \text { ALLN+STS } \\ \text { 3 CsA+STS } & 8 \text { z-FF.fmk+STS } & 13 \text { E64D+STS } \\ 4 \text { IA } 10 \mu M+S T S & 9 \text { CA-074-Me+STS } & 14 \text { epoxomicin+STS } \\ 5 \text { IA } 50 \mu M+S T S & 10 z-V A D . f m k+S T S & \end{array}$

(a)

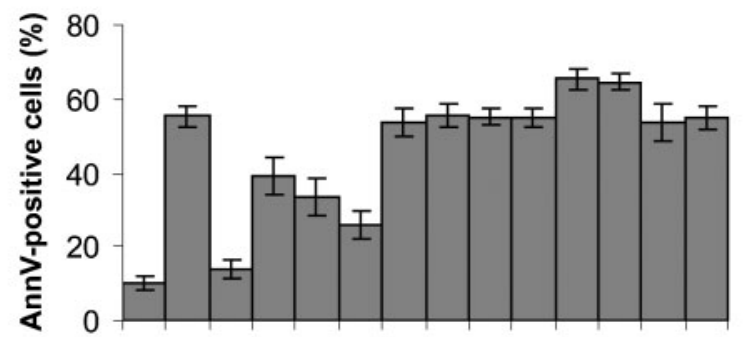

(b)

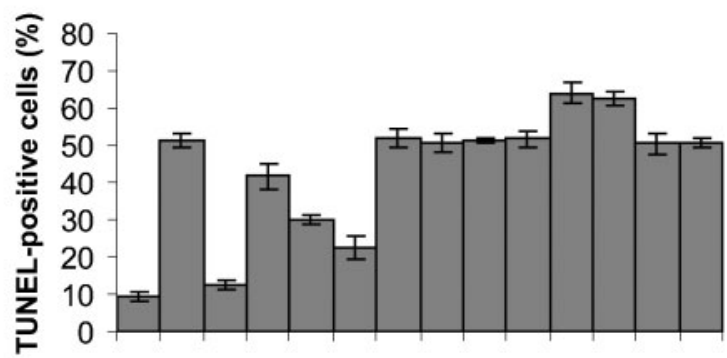

(c)

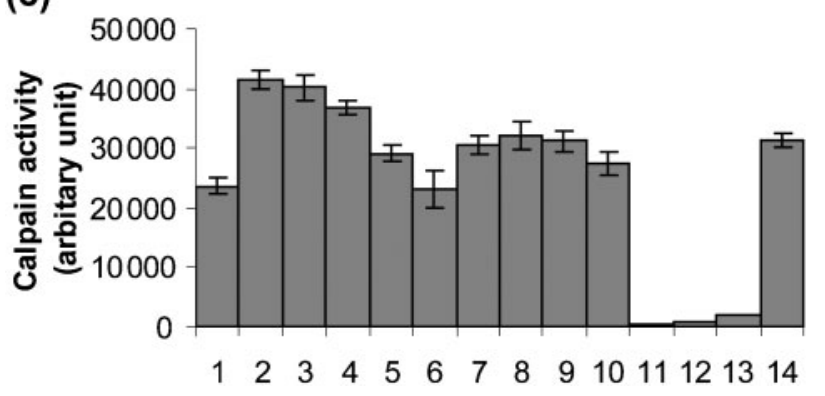

Fig. 7. Relationship between Blastocystis calpain protease activity and STS-induced apoptosis. Data from Annexin $\mathrm{V}$ and TUNEL assays were retrieved from Figs 5 and 6 . The calpain activity assay was done by incubating cell lysates with the fluorogenic substrate Ac-LLY-AFC. Values are means $\pm S D$ from three independent experiments.

and subsequent release of cytochrome $c$ and other proapoptotic molecules (Kroemer et al., 2007). Using the mitochondrial transition pore blocker CsA, we showed that mitchondria also play important roles in the execution of apoptosis induced by STS in Blastocystis, because CsA could effectively abolish STS-induced PS exposure and DNA fragmentation. In Hela cells, mitochondria have been found to have a central role in STS-induced apoptosis, and inhibition of the mitochondrial permeability transition prevents apoptosis (Tafani et al., 2001). Mitochondrial dysfunction has also been frequently observed among protozoan parasites which are induced to undergo apoptosis (Deponte, 2008). The involvement of mitochondria in PCD has been suggested to be of very ancient evolutionary origin (Arnoult et al., 2002). However, the proapoptotic molecules released by mitochondria in Blastocystis may be very different from those of mammalian cells and other protozoan parasites, given its unique taxonomic position in the kingdom Stramenopila and the presence of unusual mitochondria. The mitochondrial-like organelle in Blastocystis has been reported to lack cytochromes and to possess features of both typical mitochondria and hydrogenosomes (Lantsman et al., 2008; Stechmann et al., 2008). The amitochondrial protozoan parasites Trichomonas vaginalis and Tritrichomonas foetus have been shown to undergo apoptosislike PCD with hydrogenosome transmembrane potential disruption or altered hydrogenosomes (Chose et al., 2002; Mariante et al., 2006). Further investigation into the mitochondrial mediators of PCD in Blastocystis could shed light on how PCD arose in eukaryotes.

Despite the indispensable role of caspases in mammalian apoptosis, no orthologous sequences have been found in protozoan parasites. Nonetheless, a lot of studies have shown caspase-like activity by the cleavage of synthetic peptide substrates during cell death of protozoa, including Blastocystis (Nasirudeen et al., 2001a). It has been found that caspase-3-like activity is triggered with a cytotoxic antibody, and that inhibition of the caspase-like molecule by $\mathrm{z}$-VAD.fmk can inhibit the apoptotic features to some extent (Nasirudeen \& Tan, 2004, 2005). In contrast to the involvement of caspase-like molecules in the previous studies, the present data suggest that STS-induced apoptosis is independent of caspase-like molecules, as pretreatment with $\mathrm{z}$-VAD.fmk did not alter the PS exposure or DNA fragmentation induced by STS. However, the general cysteine protease inhibitor IA could reduce the apoptotic responses in a dose-dependent manner, suggesting the involvement of a cysteine protease in the execution of STS-induced apoptosis. As cysteine cathepsins have been suggested to regulate cell death in mammalian cells (Turk \& Stoka, 2007), the effect of inhibitors of cathepsins was examined. Three different inhibitors of cathepsins, namely z-FF.fmk (cathepsins B and L), z-FA.fmk (cathepsins B and L) and CA-074-Me (cathepsin B), were used to pretreat Blastocystis cells before exposure to STS; however, Annexin V and TUNEL assays revealed that the cathepsin inhibitors did not have any inhibitory effect on STS-induced apoptosis.

Interestingly, the calpain inhibitors z-LLL.fmk and ALLN were shown to enhance STS-induced apoptosis, while they potently inhibited calpain protease activity. Calpains are non-lysosomal calcium-dependent cysteine proteases and have been implicated in cell death signalling (Broker et al., 2005). Calpain has been reported to facilitate caspase-3 activation by initial cleavage of the pro-enzyme (Blomgren et al., 2001). Cleavage of Bax to the proapoptotic Bax/p18 has been found to be mediated by calpain and to mediate cytochrome $c$ release and the execution of apoptosis (Gao \& Dou, 2000). On the other hand, anti-apoptotic roles for calpains have also been suggested. For example, proteolytic 
cleavage of p53 protects cells from apoptosis induced by DNA damage (Kubbutat \& Vousden, 1997). Capn4-/mouse embryonic fibroblasts lack calpain activities and are more susceptible to STS- and tumour necrosis factor (TNF)- $\alpha$-induced apoptosis. The anti-apoptotic function of calpain might be related to activation of the PI3-kinase/ Akt survival pathway (Tan et al., 2006). It seems that calpains also play a protective role in STS-mediated apoptosis in Blastocystis. Identifying the substrates of calpain in Blastocystis may help to further dissect the signalling networks that regulate cell death in this organism. It is worth noting that the pretreatment with CsA blocked apoptotic features induced by STS, although calpain activity was still upregulated. Previous studies have shown that apoptotic features induced by a cytotoxic antibody in Blastocystis can be inhibited by the combined use of z-VAD.fmk and CsA, although the cells cannot be rescued from death, suggesting the existence of alternative cell death pathways in this parasite (Nasirudeen \& Tan, 2005). It is likely that despite rescue of STS-induced apoptosis by pretreatment with CsA, the cells still die through alternative cell death pathways, and thus calpain activity is upregulated as a survival response.

In conclusion, we have shown that STS can induce apoptotic features in Blastocystis, which is mediated by mitochondria and an as-yet-unidentified cysteine protease; furthermore, calpain activity is upregulated to protect the cells from apoptosis induced by STS.

\section{ACKNOWLEDGEMENTS}

This work was supported by a generous grant (R-182-000-090-305) from the Biomedical Research Council, Singapore.

\section{REFERENCES}

Al-Olayan, E. M., Williams, G. T. \& Hurd, H. (2002). Apoptosis in the malaria protozoan, Plasmodium berghei: a possible mechanism for limiting intensity of infection in the mosquito. Int J Parasitol 32, 1133-1143.

Alvarez, V. E., Kosec, G., Sant Anna, C., Turk, V., Cazzulo, J. J. \& Turk, B. (2008). Blocking autophagy to prevent parasite differentiation: a possible new strategy for fighting parasitic infections? Autophagy 4, 361-363.

Ameisen, J. C., Idziorek, T., Billaut-Mulot, O., Loyens, M., Tissier, J. P., Potentier, A. \& Ouaissi, A. (1995). Apoptosis in a unicellular eukaryote (Trypanosoma cruzi): implications for the evolutionary origin and role of programmed cell death in the control of cell proliferation, differentiation and survival. Cell Death Differ 2, 285300.

Andiran, N., Acikgoz, Z. C., Turkay, S. \& Andiran, F. (2006). Blastocystis hominis - an emerging and imitating cause of acute abdomen in children. J Pediatr Surg 41, 1489-1491.

Arnoult, D., Tatischeff, I., Estaquier, J., Girard, M., Sureau, F., Tissier, J. P., Grodet, A., Dellinger, M., Traincard, F. \& other authors (2001). On the evolutionary conservation of the cell death pathway: mitochondrial release of an apoptosis-inducing factor during Dictyostelium discoideum cell death. Mol Biol Cell 12, 30163030.

Arnoult, D., Akarid, K., Grodet, A., Petit, P. X., Estaquier, J. \& Ameisen, J. C. (2002). On the evolution of programmed cell death: apoptosis of the unicellular eukaryote Leishmania major involves cysteine proteinase activation and mitochondrion permeabilization. Cell Death Differ 9, 65-81.

Baehrecke, E. H. (2002). How death shapes life during development. Nat Rev Mol Cell Biol 3, 779-787.

Bera, A., Singh, S., Nagaraj, R. \& Vaidya, T. (2003). Induction of autophagic cell death in Leishmania donovani by antimicrobial peptides. Mol Biochem Parasitol 127, 23-35.

Blomgren, K., Zhu, C. L., Wang, X. Y., Karlsson, J. O., Leverin, A. L., Bahr, B. A., Mallard, C. \& Hagberg, H. (2001). Synergistic activation of caspase- 3 by m-calpain after neonatal hypoxia-ischemia - a mechanism of "pathological apoptosis"? J Biol Chem 276, 1019110198.

Bortner, C. D. \& Cidlowski, J. A. (1998). A necessary role for cell shrinkage in apoptosis. Biochem Pharmacol 56, 1549-1559.

Broker, L. E., Kruyt, F. A. E. \& Giaccone, G. (2005). Cell death independent of caspases: a review. Clin Cancer Res 11, 3155-3162.

Chose, O., Noel, C., Gerbod, D., Brenner, C., Viscogliosi, E. \& Roseto, A. (2002). A form of cell death with some features resembling apoptosis in the amitochondrial unicellular organism Trichomonas vaginalis. Exp Cell Res 276, 32-39.

Christensen, S. T., Chemnitz, J., Straarup, E. M., Kristiansen, K., Wheatley, D. N. \& Rasmussen, L. (1998). Staurosporine-induced cell death in Tetrahymena thermophila has mixed characteristics of both apoptotic and autophagic degeneration. Cell Biol Int 22, 591-598.

Cirioni, O., Giacometti, A., Drenaggi, D., Ancarani, F. \& Scalise, G. (1999). Prevalence and clinical relevance of Blastocystis hominis in diverse patient cohorts. Eur J Epidemiol 15, 389-393.

Collins, J. A., Schandi, C. A., Young, K. K., Vesely, J. \& Willingham, M. C. (1997). Major DNA fragmentation is a late event in apoptosis. J Histochem Cytochem 45, 923-934.

Cornillon, S., Foa, C., Davoust, J., Buonavista, N., Gross, J. D. \& Golstein, P. (1994). Programmed cell death in Dictyostelium. J Cell Sci 107, 2691-2704.

Croft, S. L., Sundar, S. \& Fairlamb, A. H. (2006). Drug resistance in leishmaniasis. Clin Microbiol Rev 19, 111-126.

Deponte, M. (2008). Programmed cell death in protists. Biochim Biophys Acta 1783, 1396-1405.

Deponte, M. \& Becker, K. (2004). Plasmodium falciparum - do killers commit suicide? Trends Parasitol 20, 165-169.

Fidock, D. A., Eastman, R. T., Ward, S. A. \& Meshnick, S. R. (2008), Recent highlights in antimalarial drug resistance and chemotherapy research. Trends Parasitol 24, 537-544.

Gao, G. \& Dou, Q. P. (2000). N-terminal cleavage of Bax by calpain generates a potent proapoptotic $18-\mathrm{kDa}$ fragment that promotes $\mathrm{Bcl}-$ 2 -independent cytochrome c release and apoptotic cell death. J Cell Biochem 80, 53-72.

Hengartner, M. O. (2000). The biochemistry of apoptosis. Nature 407, 770-776.

Ho, L. C., Singh, M., Suresh, G., Ng, G. C. \& Yap, E. H. (1993). Axenic culture of Blastocystis hominis in Iscove's modified Dulbecco's medium. Parasitol Res 79, 614-616.

Kobayashi, T. \& Endoh, H. (2005). A possible role of mitochondria in the apoptotic-like programmed nuclear death of Tetrahymena thermophila. FEBS J 272, 5378-5387.

Kroemer, G., Galluzzi, L. \& Brenner, C. (2007). Mitochondrial membrane permeabilization in cell death. Physiol Rev 87, 99-163. 
Kubbutat, M. H. \& Vousden, K. H. (1997). Proteolytic cleavage of human 53 by calpain: a potential regulator of protein stability. Mol Cell Biol 17, 460-468.

Lantsman, Y., Tan, K. S., Morada, M. \& Yarlett, N. (2008). Biochemical characterization of a mitochondrial-like organelle from Blastocystis sp. subtype 7. Microbiology 154, 2757-2766.

Madeo, F., Herker, E., Maldener, C., Wissing, S., Lächelt, S., Herlan, M., Fehr, M., Lauber, K., Sigrist, S. J. \& other authors (2002). A caspase-related protease regulates apoptosis in yeast. Mol Cell $\mathbf{9}$, 911-917.

Mariante, R. M., Vancini, R. G. \& Benchimol, M. (2006). Cell death in trichomonads: new insights. Histochem Cell Biol 125, 545-556.

McDonald, M. C., Mota-Filipe, H., Paul, A., Cuzzocrea, S., Abdelrahman, M., Harwood, S., Plevin, R., Chatterjee, P. K., Yaqoob, M. M. \& Thiemermann, C. (2001). Calpain inhibitor I reduces the activation of nuclear factor $-\kappa \mathrm{B}$ and organ injury/ dysfunction in hemorrhagic shock. FASEB J 15, 171-186.

Nasirudeen, A. M. \& Tan, K. S. (2004). Caspase-3-like protease influences but is not essential for DNA fragmentation in Blastocystis undergoing apoptosis. Eur J Cell Biol 83, 477-482.

Nasirudeen, A. M. \& Tan, K. S. (2005). Programmed cell death in Blastocystis hominis occurs independently of caspase and mitochondrial pathways. Biochimie 87, 489-497.

Nasirudeen, A. M., Singh, M., Yap, E. H. \& Tan, K. S. (2001a). Blastocystis hominis: evidence for caspase-3-like activity in cells undergoing programmed cell death. Parasitol Res 87, 559-565.

Nasirudeen, A. M. A., Tan, K. S. W., Singh, M. \& Yap, E. H. (2001b). Programmed cell death in a human intestinal parasite, Blastocystis hominis. Parasitology 123, 235-246.

Nasirudeen, A. M., Hian, Y. E., Singh, M. \& Tan, K. S. (2004). Metronidazole induces programmed cell death in the protozoan parasite Blastocystis hominis. Microbiology 150, 33-43.

Stechmann, A., Hamblin, K., Perez-Brocal, V., Gaston, D., Richmond, G. S., van der Giezen, M., Clark, C. G. \& Roger, A. J. (2008). Organelles in Blastocystis that blur the distinction between mitochondria and hydrogenosomes. Curr Biol 18, 580-585.

Stensvold, C. R., Nielsen, H. V., Molbak, K. \& Smith, H. V. (2009). Pursuing the clinical significance of Blastocystis - diagnostic limitations. Trends Parasitol 25, 23-29.

Tafani, M., Minchenko, D. A., Serroni, A. \& Farber, J. L. (2001). Induction of the mitochondrial permeability transition mediates the killing of HeLa cells by staurosporine. Cancer Res 61, 24592466.

Tan, K. S. (2004). Blastocystis in humans and animals: new insights using modern methodologies. Vet Parasitol 126, 121-144.

Tan, K. S. (2008). New insights on classification, identification, and clinical relevance of Blastocystis spp. Clin Microbiol Rev 21, 639-665.

Tan, K. S. \& Nasirudeen, A. M. (2005). Protozoan programmed cell death - insights from Blastocystis deathstyles. Trends Parasitol 21, 547-550.

Tan, Y., Wu, C., De Veyra, T. \& Greer, P. A. (2006). Ubiquitous calpains promote both apoptosis and survival signals in response to different cell death stimuli. J Biol Chem 281, 17689-17698.

Tasova, Y., Sahin, B., Koltas, S. \& Paydas, S. (2000). Clinical significance and frequency of Blastocystis hominis in Turkish patients with hematological malignancy. Acta Med Okayama 54, 133-136.

Taylor, R. C., Cullen, S. P. \& Martin, S. J. (2008). Apoptosis: controlled demolition at the cellular level. Nat Rev Mol Cell Biol 9, 231-241.

Turk, B. \& Stoka, V. (2007). Protease signalling in cell death: caspases versus cysteine cathepsins. FEBS Lett 581, 2761-2767.

Vardi, A., Berman-Frank, I., Rozenberg, T., Hadas, O., Kaplan, A. \& Levine, A. (1999). Programmed cell death of the dinoflagellate Peridinium gatunense is mediated by $\mathrm{CO}_{2}$ limitation and oxidative stress. Curr Biol 9, 1061-1064.

Vaux, D. L., Haecker, G. \& Strasser, A. (1994). An evolutionary perspective on apoptosis. Cell 76, 777-779.

Weil, M., Jacobson, M. D., Coles, H. S., Davies, T. J., Gardner, R. L., Raff, K. D. \& Raff, M. C. (1996). Constitutive expression of the machinery for programmed cell death. J Cell Biol 133, 1053-1059.

Welburn, S. C., Dale, C., Ellis, D., Beecroft, R. \& Pearson, T. W. (1996). Apoptosis in procyclic Trypanosoma brucei rhodesiense in vitro. Cell Death Differ 3, 229-236.

Zangger, H., Mottram, J. C. \& Fasel, N. (2002). Cell death in Leishmania induced by stress and differentiation: programmed cell death or necrosis? Cell Death Differ 9, 1126-1139.

Zhang, X. D., Gillespie, S. K. \& Hersey, P. (2004). Staurosporine induces apoptosis of melanoma by both caspase-dependent and independent apoptotic pathways. Mol Cancer Ther 3, 187-197.

Edited by: L. J. Knoll 